\title{
Variation in sex-, stage- and tissue-specific expression of the amylase genes in Drosophila ananassae
}

\author{
JEAN-LUC DA LAGE*, ALBERT KLARENBERG + \& MARIE-LOUISE CARIOU \\ UPR Populations, Génétique et Évolution, CNRS, 91198 Gif sur Yvette cedex, France and †Zoologisches Institut der \\ Universität München, Seidlstrasse 25, D.80335 München, Germany
}

\begin{abstract}
Expression of the amylase multigene family of Drosophila ananassae was investigated in thirdinstar larvae and adults. A developmental differentiation was found between the Amy1-2 and Amy3-4 gene clusters, the former being preferentially expressed in larvae, the latter in adults. During adult life, we observed a decrease in $A m y 1-2$ expression in males of certain strains. We have raised some arguments for the existence of trans-active regulators, acting as repressors of Amy1-2 in adults. The putative repressors might exhibit a geographical polymorphism, with a fixed active form in Pacific regions and a polymorphic pattern in Africa, thus increasing the diversity observed in adult amylase phenotypes. A clear differentiation between the two gene clusters was also found in tissue-specific activity along the third-instar larval midgut. In the anterior midgut, only Amy1-2 is active, while both gene groups are expressed in the posterior midgut, with an additional subzonation within it.
\end{abstract}

Keywords: amylase, Drosophila ananassae, gene duplication, gene regulation, midgut, multigene family.

\section{Introduction}

Amylases, which have been extensively studied in many organisms for the past 30 years, are directly involved in digestive processes. Since there may be a strong interaction between the gene-enzyme system and environment, i.e. the nutritive substrate, this enzyme is of great interest from an evolutionary point of view.

Duplications of the Amy coding genes have been described in a number of nonrelated animal species, such as man (Gumucio et al., 1988), other mammals (Crerar \& Rooks, 1987), Crustacea (Borowski et al., 1985; Oxford, 1986; Laulier, 1988), Coleoptera (Pope et al., 1986), Lepidoptera (Kikkawa, 1953), and Diptera. Within the Drosophilid family, duplications were first evidenced in Drosophila melanogaster (Kikkawa, 1964; Bahn, 1967) and confirmed for all the species of the melanogaster subgroup (Daïnou et al., 1987; Payant et al., 1988; Shibata and Yamazaki, submitted). Several Amy genes are also known for D. pseudoobscura (Brown et al., 1990), the D. ananassae subgroup (Da Lage et al., 1989, 1992),

\footnotetext{
${ }^{*}$ Correspondence.
}

and most of the species of the D. melanogaster group (Tadlaoui et al., submitted).

The cosmopolitan tropical species Drosophila ananassae shows the most complex amylase gene system described until now in Drosophilids. A total of 13 different amylase variants have been recognized with gel electrophoresis. There is a marked geographical polymorphism of these variants, which is not consistent with the Asiatic origin of the ananassae subgroup because the African populations are the most polymorphic ones. At least four potentially active genes exist, organized as two independent pairs of closely linked copies which are located on different chromosomes, namely Amy1,2 and Amy3,4. Several alleles have been identified at each locus, including a putative null allele (Da Lage $e t$ al., $1989,1992)$. Since the beginning of our studies on $D$. ananassae, we suspected that regulatory phenomena could be involved in modifying the expression of amylase electrophoretic patterns. It appeared that segregation of amylase variants was generally Mendelian; however, in some crosses unexpected bands were also observed.

Tissue-specific expression in the midgut, in the anterior and posterior midgut (AMG, PMG) only, 
appears to be a typical characteristic of Drosophila amylase activity. Similar patterns are found in $D$. pseudoobscura (Powell \& Lichtenfels, 1979), D. hydei (Doane, 1969) and D. melanogaster (Doane, 1969; Abraham \& Doane, 1978; Klarenberg \& Scharloo, 1986). In D. melanogaster it is controlled by the trans-acting map (Midgut Activity Pattern) gene which has been well studied (Doane et al., 1983). A further independent genetic control (a closely linked cis-acting element) of amylase distribution in the anterior midgut of third-instar larvae was evidenced later (Klarenberg et al., 1986). In D. pseudoobscura it was concluded that the genetic control was polygenic (Powell \& Lichtenfels, 1979).

The present study reports first, differential expression of the amylase genes during development that may partially explain the geographical pattern of amylase variants observed among populations of $D$. ananassae, and secondly, differences between the two gene clusters in amylase midgut tissue-specific expression.

\section{Materials and methods}

The $D$. ananassae strains used for the geographical polymorphism studies are listed in Table 1. Techniques for vertical gel electrophoresis were described by Da Lage et al. (1989). Tissue-specific expression of amylase variants along dissected midguts revealed by electrophoresis of intact midguts was investigated as described by Klarenberg et al. (1986). The flies were reared and fed on axenic, nonsugared and dead yeast-rich medium prior to electrophoresis to allow maximal amylase expression (David \& Clavel, 1965). In D. melanogaster, glucose and other sugars added to the food medium may strongly repress amylase activity (Benkel \& Hickey, 1986; Klarenberg et al., 1988). In contrast to adults of $D$. ananassae, we have found a significant effect of glucose in larvae ( $\mathrm{Da}$ Lage, 1990). Larvae were assayed at the third instar feeding stage and it is the only larval stage considered in this study. Pupae failed to show any amylase activity other than traces of larval proteins.

\section{Results}

Larval vs. adult expression of amylase in D. ananassae

In most $D$. ananassae strains, adult electrophoretic amylase patterns are different from the larval ones. Some of the amylase variants may be absent in adults while common in larvae, and vice versa. Therefore the frequencies of electromorphs in adult populations may change drastically when compared to those of the corresponding larvae. As an example, Table 2 gives a comparison of the occurrence of different amylase variants observed in adults and larvae from a mass strain freshly collected in the

Table 1 Drosophila ananassae strains used in this study. Several old strains from the Pacific Ocean were supplied by the Bowling Green Drosophila Stock Center

\begin{tabular}{lllll}
\hline Strain & Symbol & $\begin{array}{l}\text { Geographical } \\
\text { origin }\end{array}$ & Observations & $\begin{array}{c}\text { Date of } \\
\text { collection }\end{array}$ \\
\hline $0371-3$ & $\mathrm{Hw}$ & Hawaii & Bowling Green & 1962 \\
$0371-8$ & $\mathrm{Py}$ & Palmyra & Bowling Green & 1962 \\
$0371-13$ & $\mathrm{Tg}$ & Tonga & Bowling Green & 1962 \\
Takapoto & $\mathrm{Tk}$ & Tuamotu Is. & 16 isofemale lines & 1986 \\
Mexico & $\mathrm{Mx}$ & Mexico & 2 isofemale lines & 1987 \\
Cuba & $\mathrm{Cb}$ & Cuba & 2 isofemale lines & 1989 \\
Sao Paulo & $\mathrm{SP}$ & Brazil & 1 isofemale line & 1987 \\
Guadeloupe & $\mathrm{G}$ & West Indies & Mass strain & 1986 \\
Martinique & $\mathrm{Mq}$ & West Indies & 6 isofemale lines & 1988 \\
Taï & $\mathrm{T}$ & Ivory Coast & Mass strain & 1983 \\
Djeffa & $\mathrm{Dj}$ & Benin & 8 isofemale lines & 1987 \\
Brazzaville & $\mathrm{Bz}$ & Congo & Mass strain & 1989 \\
Maroantsetra & $\mathrm{Mt}$ & Madagascar & 19 isofemale lines & 1987 \\
Réunion & $\mathrm{R}$ & Reunion Is. & Mass strain & 1987 \\
Varanasi & $\mathrm{V}$ & India & 7 isofemale lines & 1987 \\
Korat & $\mathrm{K}$ & Thailand & 30 isofemale lines & 1989 \\
Noumea & $\mathrm{N}$ & New Caledonia & Mass strain & 1987 \\
\hline
\end{tabular}


Table 2 Frequency (per cent) of amylase variants in adults and third-instar larvae in a recently collected Drosophila ananassae population from Congo

\begin{tabular}{lrllllr}
\hline & \multicolumn{4}{c}{ Amy gene clusters } \\
\cline { 2 - 4 } & \multicolumn{3}{c}{ Amy1-2 } & & \multicolumn{3}{c}{ Amy3-4 } \\
\cline { 2 - 4 } \cline { 6 - 7 } Amylase variants & \multicolumn{1}{c}{1} & 1 & $2^{\prime}$ & & 3 & 4 \\
\hline Adults $(n=48)$ & 2 & 21 & 85.5 & & 100 & 100 \\
Larvae $(n=46)$ & 89 & 65 & 87 & & 100 & 96 \\
\hline
\end{tabular}

Congo. The data show that amylase variants belonging to the Amyl-2 gene cluster are significantly more frequently expressed in larvae than in adults. The gel in Fig. 1(a) illustrates the high diversity of larval phenotypes, which are usually more complex than those of corresponding adults. Moreover, in natural populations there is a variation in band intensity of the different electromorphs within a single larva, as well as between larvae from the same strain, which is more important than in adults.

The use of inbred lines, made homozygous for adult $A m y$ gene expression, or found to be so (in old laboratory stocks from the Bowling Green Center, for example), shows more clearly the temporal specificity of expression of the different amylases, as illus-

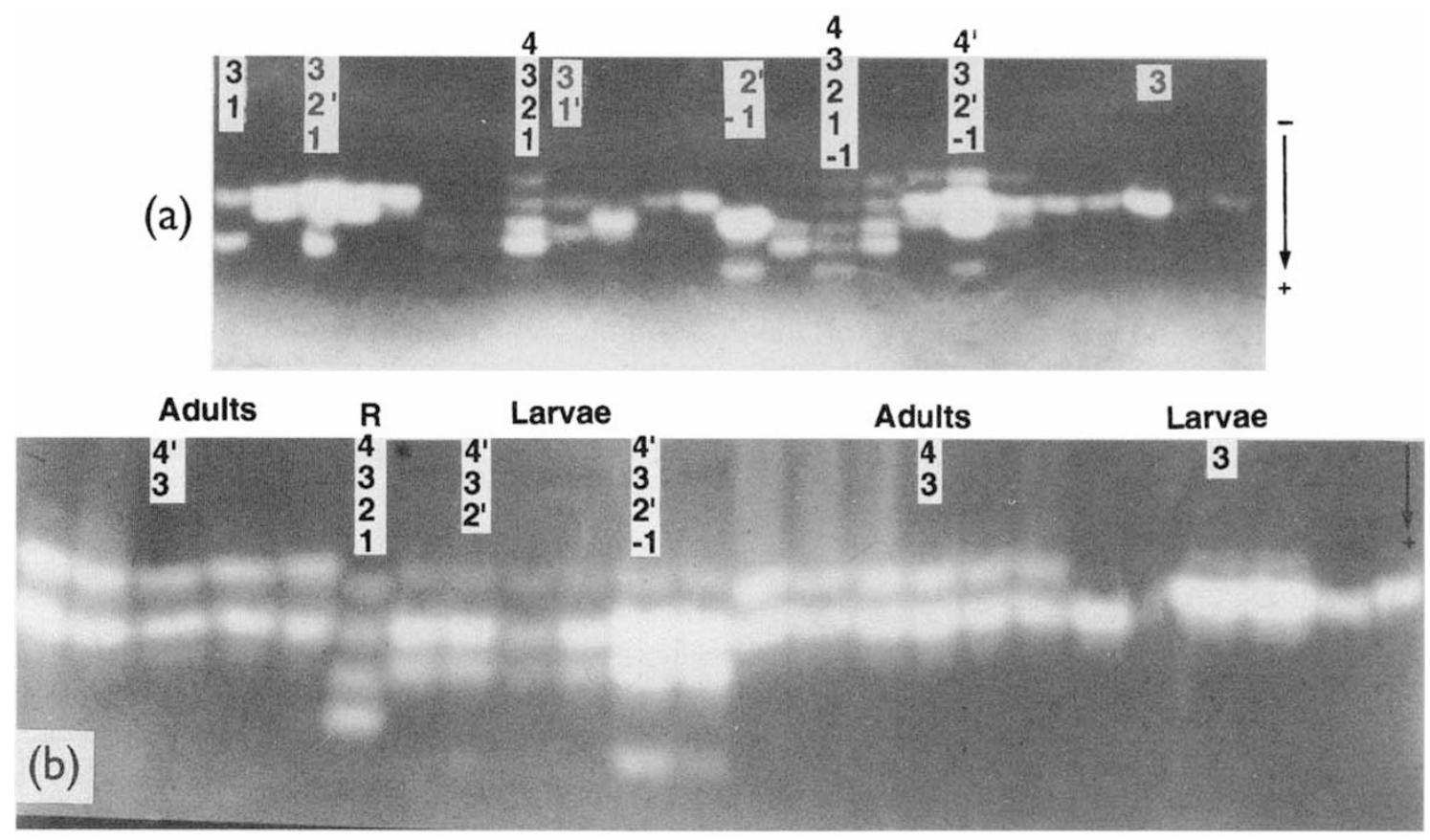

(c)

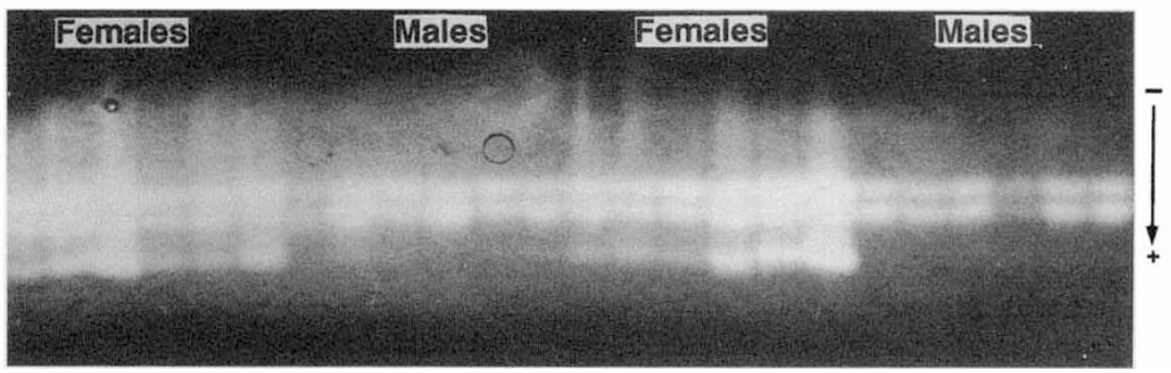

Fig. 1 (a) Larval amylase phenotypes from various Drosophila ananassae strains. Lanes 1-5, Maroantsetra (Madagascar); lanes 6-8, Taï 13-1610; lane 9, Taka 5; lanes 10-13, Takapoto (French Polynesia); lanes 14-16, Taï 13-1610; lanes 17-19, 371-3 (Hawaii); lanes 20-23, 371-1 (Mexico). (b) Adult and larval amylase phenotypes of two homozygous lines: lanes

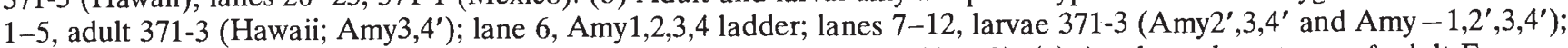
lanes 13-18, adults 371-1 (Mexico; Amy3,4); lanes 19-24, larvae 371-1 (Amy3). (c) Amylase phenotypes of adult $F_{1}$ progenies from crosses between female Taï 13-1610 (Amy1,2,3,4) and male Taka 5 (Amy3): lanes 1-6, female F1-3; lanes 7-12, male F1-3; lanes 13-18, female F1-4; lanes 19-24, male F1-4 (indicated with asterisks in Table 3). 
trated by Fig. 1(b) and Table 2. The fastest amylase electromorphs (Amy-1, Amy1, Amy1', Amy2, Amy $2^{\prime}$ ) are more frequent in larvae than in adults, while slow variants (Amy3, Amy4, Amy4', Amy5) are much more frequent in adults and may be absent in larvae, although it is rare for Amy3 (see Fig. 1a, lane 13). In addition, the screening of populations from the whole geographical range of the species (see Da Lage et al., 1989) allows us to identify the larval bands: in the Pacific region, where only Amy3 and Amy4 (replaced by Amy4' in Hawaii) are known for adults, several faster bands are found in larvae, which migrate similarly to electromorphs already described from African adult patterns (Amy-1, Amy2'). The only exception is Amy1', which has never been observed in any wild adult. Thus, Amy1' is the only strictly larval amylase (see Fig. 1a; Fig. 4). Its geographical range is limited to the Pacific region.

Figure 2 shows the geographical distribution of pooled larval and adult amylase variants. The distribution of adult amylase variants reveals a striking disequilibrium in terms of allelic richness and phenotypic diversity between Africa, on the one hand, and far-Eastern and Pacific regions on the other (Da Lage et al., 1989). When both adults and larvae are considered, the Pacific region appears more polymorphic and the disequilibrium between these two regions is reduced. This point will be discussed below.

From the observations reported above, it is possible to classify the most common amylase variants according to their temporal regulation patterns: Amy - 1, Amy1, Amy1', Amy 2 and Amy2' belong to a group which is expressed in larvae and may be repressed at various levels in adults; Amy3, Amy4, Amy4' and Amy5 may be considered as preferentially adult amylases. This classification is illustrated in Fig. 3. Interestingly, the pattern of temporal expression of amylase is strongly correlated with the structural organization of the amylase genes in two clusters located on two different chromosomes: the Amy1-2 and Amy3-4 gene blocks. We may infer that Amy1' might be an allele of Amy1, substituted for it in Pacific regions. Amy4' and Amy5 are supposed to be alleles of Amy4, Amy4' replacing Amy4 in Hawaii (Da Lage et al., 1992). Amy-1 has not been assigned to any locus yet. It might be encoded by a fifth gene close to $A m y$ l. The rare amylase variants (Amy5', Amy6, Amy7, Amy8 and Amy9; see Fig. 2) are not considered here.

Although the distinction is not strict, the Amy1-2 complex may be considered as a larval system and Amy3-4 as an adult system. When larval and adult patterns were compared, we noticed that expression of the Amyl-2 complex was generally more affected

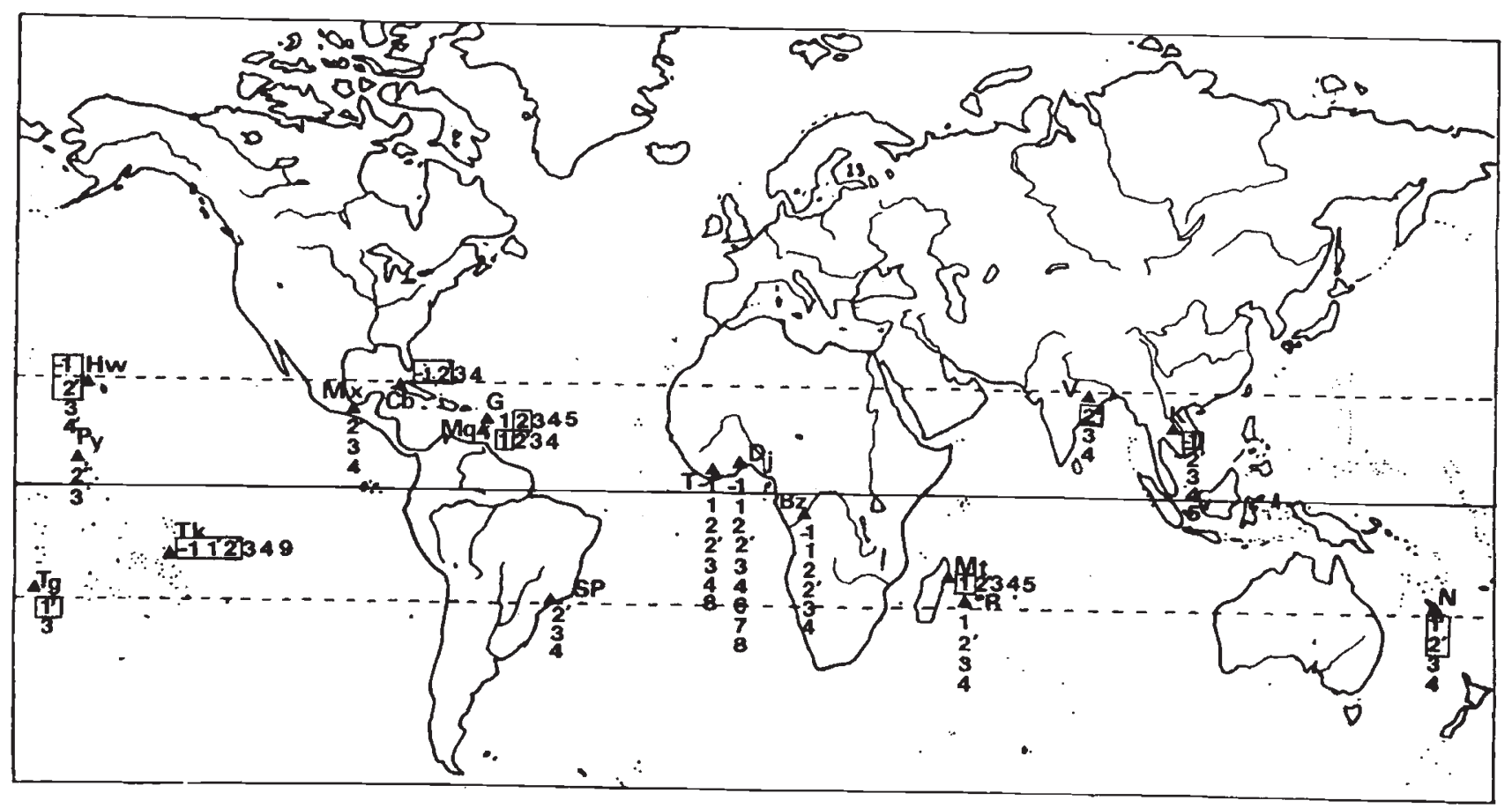

Fig. 2 Geographical distribution of larval and adult amylases in Drosophila ananassae. Electromorphs which are expressed only in larvae are boxed. 
Complex "3-4"
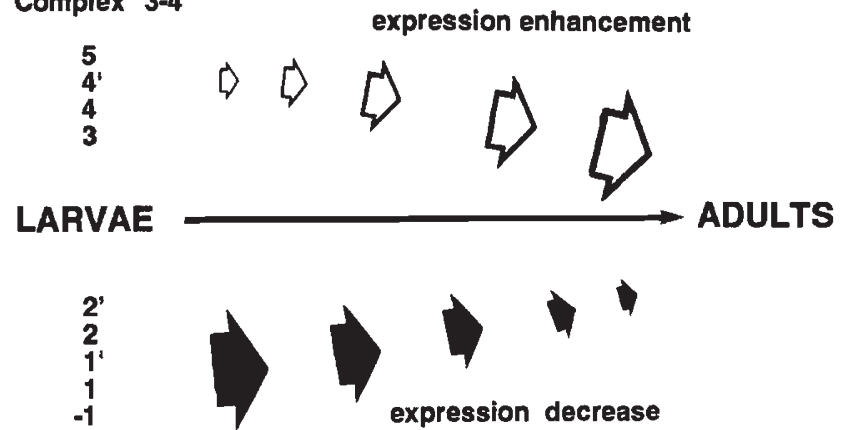

Complex "1-2"

Fig. 3 Schematic diagram of the differential regulatory patterns for temporal expression in Drosophila ananassae. Amylase electromorphs were classified in two groups according to their temporal expression preferences. These groups coincide with the two gene clusters $A m y 1-2$ (larval) and Amy3-4 (adult). Variants Amy-1 Amy1 and Amy1' segregate at locus Amy1; Amy2 and Amy2' at locus Amy2; Amy4, Amy4' and Amy5 at locus Amy4; locus Amy3 has only one active allele in addition to a null allele (Da Lage et al., 1992).

by the regulation than that of Amy3-4. We have thus assumed the existence of some regulatory factors for the Amy1-2 complex, such as a putative repressor gene active in adult flies, or a putative activator gene active in larvae.

\section{Effect of age and sex on adult amylase expression}

To analyse the temporal expression in adult flies, the electrophoretic phenotypes of individuals from the selected strain Taï 13-1610 (homozygous for Amy1,2,3,4) and some derived strains (described in the next section) were observed at various times after emergence: $6 \mathrm{~h}, 24 \mathrm{~h}, 3$ days and 8 days. For this purpose, flies were transferred to fresh axenic medium immediately after emergence. At $6 \mathrm{~h}$, only slow amylases (Amy3-4 group) were expressed. At $24 \mathrm{~h}$, all proteins were produced with maximal intensity. After three days, amylase activity decreased irregularly according to the strain, affecting especially Amy1 and Amy2 in some males, so that in substrain $1610 \mathrm{SD}$, 8-day-old males showed an almost typical Amy3,4 pattern while females remained Amy1,2,3,4, as expected.

\section{Genetic analyses of sex-and stage-specific amylase expression in adults}

The hypothesis of the existence of putative adultrepressor genetic elements acting on fast amylases is supported by the following genetic analyses. Three
$D$. ananassae strains homogeneous for adult phenotypes were used in crossing experiments: Taï 13-1610 (Amy1,2,3,4), T404 (Amy4) and Taka 5 (Amy3). The Taka 5 and T404 lines were derived from the same Pacific population (Takapoto), and lack Amy1-2 expression in adults. Taï 13-1610 was extracted from an Ivory Coast strain, in which the Amy1-2 gene cluster is active in a number of adults in addition to Amy3-4. Reciprocal crosses were designed between Taï 13-1610 (Amy1,2,3,4) and either Taka 5 (Amy3) or T404 (Amy4). The experiment was repeated several times within a three-year period. As we have shown (see above) that the typical Amy1,2,3,4 pattern of the African parental strain may be modified in 8-day-old flies, only flies younger than three days were used for electrophoresis. Males and females were determined in the $F_{1}$ progenies before electrophoresis. Amy1 and Amy2 activities were estimated visually on the gels for each individual as 'strong' or 'weak-none'. Results are given in Table 3. Because of the Mendelian inheritance of amylase variants, in these types of crosses $F_{1}$ phenotypes are expected to be 100 per cent Amy1,2,3,4 and this was indeed the case in many $\mathrm{F}_{1} \mathrm{~s}$ (see also Da Lage et al., 1992). However, in some $F_{1} s$, an unexpected and striking repression of Amy1 and Amy2 in $F_{1}$ males was observed (Fig. 1c) when Pacific single-band parents were used (Amy3 or Amy4), and in both crossing directions (male or female Amy1,2,3,4). The repression of amylase activity clearly affected males in particular, although in crosses showing a very strong effect, a decrease of Amy2 intensity was also apparent in females. However, ANOvas were performed only on males. The statistical analyses reveal no effect of the amylase variant (Amy1 vs. Amy2); that is, Amy1 and Amy2 were coordinately regulated. These two variants are known to be encoded by two closely linked loci. A significant variability between repeats ('year') was found in two of the three sorts of crosses for which several repeats had been carried out. The latter point is discussed below.

To explain this unexpected repression of $A m y 1,2$ genes, we suggest the existence of repressor elements: in Pacific strains, an active form of a repressor system should be present, because fast amylases are lacking in adults but are present in larvae (T404 is Amy1',4 in larvae vs. Amy4 in adults). In the African parent Amy1,2,3,4, the repressor system would be inactive, allowing expression of the Amy1-2 complex in adults as well as in larvae. In $F_{1}$ hybrids, the active repressor(s) inherited from the single-band parent would exhibit a trans-activity, thus repressing the Amyl and Amy2 structural genes inherited from the four-band 
Table 3 Expression of Amy1 and Amy2 variants in $F_{1}$ progenies of crosses between Taï 13-1610 (Amy1,2,3,4) and either Taka 5 (Amy3) or T404 (Amy4) strains of Drosophila ananassae

\begin{tabular}{|c|c|c|c|c|c|c|c|c|c|c|}
\hline & & \multicolumn{2}{|c|}{$\mathrm{F}_{1}$ males } & \multicolumn{2}{|c|}{$F_{1}$ females } & \multicolumn{5}{|c|}{ Analysis of variance (males only) } \\
\hline & & $\begin{array}{c}\text { Amy1 } \\
\text { expression }\end{array}$ & $\begin{array}{c}\text { Amy2 } \\
\text { expression }\end{array}$ & $\begin{array}{c}\text { Amy1 } \\
\text { expression }\end{array}$ & $\begin{array}{c}\text { Amy2 } \\
\text { expression }\end{array}$ & Source & d.f. & SS & MS & $F$ \\
\hline \multicolumn{11}{|c|}{ A. Female Amy $1,2,3,4 \times$ male Amy 4} \\
\hline \multirow{8}{*}{1989} & F1-1 & 0 & 0 & 6 & 2 & Amy & 1 & 4 & 4 & 1.14 \\
\hline & F1-2 & 2 & 0 & 6 & 6 & Residual & 14 & 49 & 3.5 & \\
\hline & F1-3 & 4 & 4 & 6 & 6 & & & & & \\
\hline & F1-4 & 0 & 0 & 6 & 6 & & & & & \\
\hline & F1-5 & 4 & 4 & 6 & 6 & & & & & \\
\hline & F1-6 & 3 & 2 & 6 & 6 & & & & & \\
\hline & F1-7 & 3 & 2 & 6 & 6 & & & & & \\
\hline & F1-8 & 6 & 2 & 6 & 6 & & & & & \\
\hline \multicolumn{11}{|c|}{ B. Female Amy $1,2,3,4 \times$ male Amy 3} \\
\hline \multirow[t]{7}{*}{1989} & F1-1 & 0 & 0 & 6 & 3 & Amy & 1 & 0.036 & 0.036 & 0.026 \\
\hline & F1-2 & 0 & 0 & 6 & 5 & Among (year) & 2 & 164.2 & 82.1 & $59.5^{* * *}$ \\
\hline & $\uparrow \mathrm{F} 1-3$ & 0 & 0 & 6 & 4 & Amy $\times$ year & 2 & 0.027 & 0.013 & 0.010 \\
\hline & $\dagger F 1-4$ & 0 & 0 & 3 & 3 & Residual & 22 & 30.4 & 1.38 & \\
\hline & F1-5 & 1 & 0 & 6 & 6 & & & & & \\
\hline & F1-6, F1-8 & 0 & 0 & 6 & 6 & & & & & \\
\hline & F1-7 & 0 & 0 & 6 & 4 & & & & & \\
\hline 1991 & $\mathrm{~F} 1-1, \mathrm{~F} 1-2$ & 6 & 6 & 6 & 6 & & & & & \\
\hline \multirow[t]{3}{*}{1992} & F1-1 & 1 & 1 & 6 & 6 & & & & & \\
\hline & $\mathrm{F} 1-2$ & 6 & 6 & 4 & 4 & & & & & \\
\hline & F1-3, F1-4 & 5 & 5 & 6 & 6 & & & & & \\
\hline \multicolumn{11}{|c|}{ C. Female Amy $4 \times$ male Amy $1,2,3,4$} \\
\hline \multirow[t]{4}{*}{1989} & F1-1 & 2 & 1 & 6 & 5 & Amy & 1 & 0.285 & 0.285 & 0.046 \\
\hline & F1-2 & 3 & 2 & 6 & 6 & Among (year) & 1 & 17.15 & 17.15 & 2.79 \\
\hline & F1-3, F1-5 & 6 & 6 & 6 & 6 & Amy $\times$ year & 1 & 0.114 & 0.114 & 0.019 \\
\hline & F1-4 & 0 & 0 & 6 & 6 & Residual & 10 & 61.4 & 6.14 & \\
\hline \multirow[t]{2}{*}{1991} & F1-1 & 0 & 0 & 6 & 6 & & & & & \\
\hline & F1-2 & 1.5 & 1.5 & 5.25 & 5.25 & & & & & \\
\hline \multicolumn{11}{|c|}{ D. Female Amy $3 \times$ male Amy 1,2,3,4 } \\
\hline 1989 & F1-1 to F1-8 (each) & 6 & 6 & 6 & 6 & Amy & 1 & 0 & 0 & 0 \\
\hline \multirow[t]{2}{*}{1991} & F1-1, F1-2 & 0 & 0 & 6 & 6 & Among (year) & 2 & 96.8 & 48.4 & $7.75^{*}$ \\
\hline & F1-3 & 6 & 6 & 6 & 6 & Amy $\times$ year & 2 & 0 & 0 & 0 \\
\hline \multirow{7}{*}{1992} & F1-1 & 1 & 1 & 6 & 6 & Residual & 44 & 274.8 & 6.247 & \\
\hline & F1-2 & 0 & 0 & 5 & 2 & & & & & \\
\hline & $\mathrm{F} 1-3, \mathrm{~F} 1-4$ & 6 & 6 & 6 & 6 & & & & & \\
\hline & $\begin{array}{l}\text { F1-5, F1-6 } \\
\text { F1-7 }\end{array}$ & $\begin{array}{l}0 \\
5\end{array}$ & $\begin{array}{l}0 \\
5\end{array}$ & $\begin{array}{l}6 \\
6\end{array}$ & $\begin{array}{l}6 \\
5\end{array}$ & & & & & \\
\hline & F1-8 & 0 & 0 & $\begin{array}{l}0 \\
6\end{array}$ & $\begin{array}{l}5 \\
6\end{array}$ & & & & & \\
\hline & F1-9 to F1-13 (each) & 6 & 6 & 6 & 6 & & & & & \\
\hline & F1-14 & 0 & 0 & 6 & 6 & & & & & \\
\hline
\end{tabular}

For each progeny, six males and six females were assayed by gel electrophoresis, except in the cross of series C, F1-2, 1991 for which values were standardized to 6 .

Amy1 and Amy 2 patterns were scored as +1 if strongly expressed, and 0 if weak or not expressed. Scores thus range from 0 (no expression for any of the six flies assayed) to 6 (strong expression in the six flies assayed).

ANOVAS were performed for males to test repeats of crosses within a three-year period and the coregulation of Amyl and Amy2.

${ }^{*} P<0.05 ;{ }^{* *} P<0.001$ (Type 1 anova with proportional subclass number (Sokal \& Rohlf, 1995)). Female patterns were almost always typically Amy1,2,3,4.

$\uparrow F_{1}$ s illustrated in Fig. 1(c). 
parent. The existence of adult repressor genes of the Amy1-2 cluster is well supported by these crossing experiments. However, the restriction of the repressive effect to males remains unexplained yet, though it is clear that the relevant genetic elements are not carried by the $\mathrm{X}$ chromosome (or at least not all of them if several genetic elements are involved). The variability of the response of the different $F_{1} S$ to repression may result from a polygenic structure of the repressor system and/or heterogeneity of the sensitive Taï 13-1610 strain with respect to this regulation. We attempted to reduce the genetic heterogeneity of Taï 13-1610 using substrains which were derived by isolating inseminated females for several generations. Three substrains (1610SD, 1610SE, $1610 \mathrm{VCC})$ were crossed to the unchanged singleband strains Amy3 and Amy4. Until now, we failed to select a strain constantly sensitive to the repressing factor, but for the strain $1610 \mathrm{VCC}$, no repression at all was found in any type of cross with this strain (not shown). Thus, the variable response of Taï 13-1610 to the repressor could result from its residual heterogeneity, because this strain was selected for adult amylase phenotype only, and kept for several years as a mass strain. The heterogeneity between repetitions of the experiments during the past three years may be because of drift in the Taï 13-1610 strain. Two series of backcrosses were performed to try to demonstrate the genetical determination of repression: $F_{1}$ males with strongly repressed Amy1,2 activity (phenotypically Amy3,4)

were isolated from the offspring of crosses between either female Taï 13-1610 and male Taka 5 or reciprocally (genotypically Amy1,2,3,4/Amy3). They were mated to Taka 5 (parental Amy3) females. Under the hypothesis of a simple determinism, a repressive effect could still be expected, leading to an excess of Amy3 and Amy3,4 phenotypes among the four possible phenotypes Amy3, Amy3,4, Amy1,2,3 and Amy1,2,3,4. Instead, the results showed no significant disequilibrium (data not shown) although the Amy2 band often remained weak in backcross phenotypes. Thus, the determination may be rather complex.

\section{Tissue-specific expression of amylase}

The major sites of amylase activity in Drosophila are the larval and adult midguts. In $D$. ananassae, in situ histochemical detection of amylase activity in intact midguts clearly shows that the protein is expressed only in the AMG and PMG but not in the middle midgut (MMG). Electrophoresis of intact adult and larval midguts of strains Taï 13-1610 and T404 confirms the differential distribution of amylase activity (Fig. 4). This shows a more original result: in strains which have a functional Amy1-2 group, thirdinstar larvae show a strongly differentiated expression between the two gene clusters. In the PMG, both gene clusters are active (Taï 13-1610, T404) or the Amy3-4 group alone (Taka 5), while in the AMG, only fast amylases (Amy1-2 group) are found.

Larvae
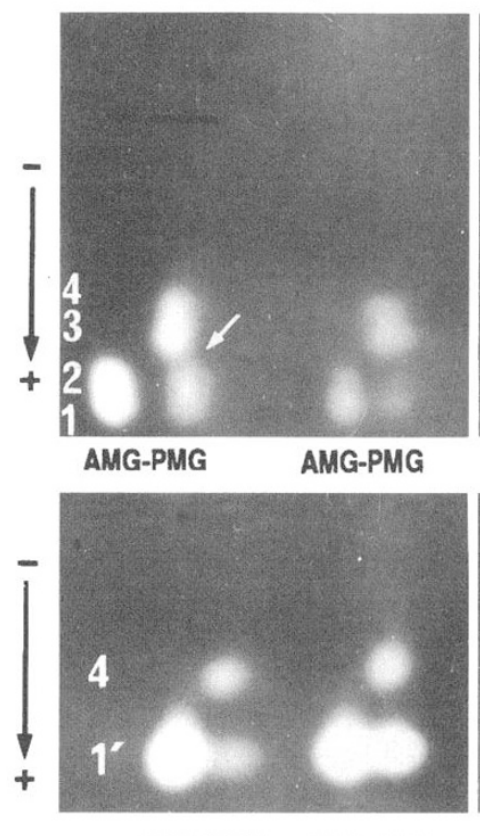

AMG-PMG
Adults
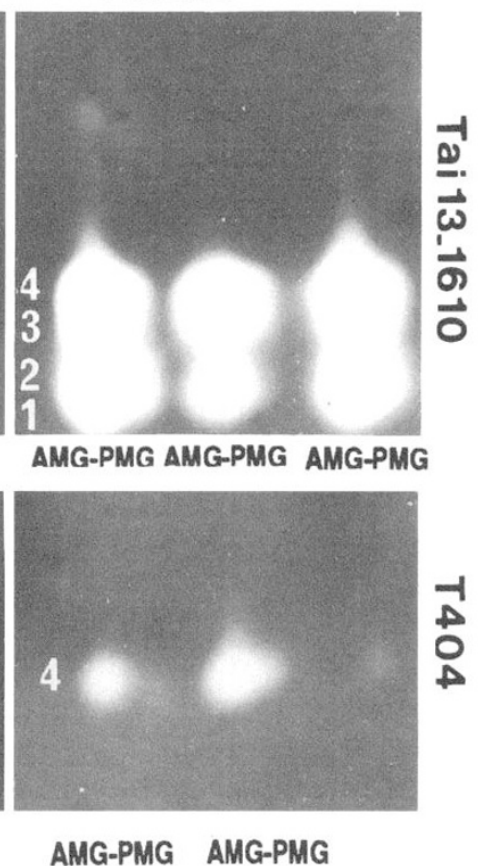
the AMG. 
Table 4 Tissue-specific expression of amylase genes in the midgut of third-instar larval and adult Drosophila ananassae

\begin{tabular}{lllll}
\hline Strains & & $\begin{array}{l}\text { Amylase } \\
\text { phenotypes }\end{array}$ & $\begin{array}{l}\text { Expression } \\
\text { in AMG }\end{array}$ & $\begin{array}{l}\text { Expression } \\
\text { in PMG }\end{array}$ \\
\hline Taï 13-1610 & adults & Amy1,2,3,4 & $1,2,3,4(+++)$ & $1,2,3,4(+++)$ \\
& larvae & Amy1,2,3,4 & $1,2(+++)$ & $1,2(+) 3,4(+++)$ \\
T404 & adults & Amy4 & $4(+++)$ & - \\
& larvae & Amy1',4 & $1^{\prime}(+++)$ & $1^{\prime}(+) 4(+)$ \\
Taka 5 & adults & Amy3 & $3(+++)$ & $3(+)$ \\
& larvae & Amy1',3 & $1^{\prime}(+++)$ & $3(++)$ \\
$371-1$ & adults & Amy3,4 & $3,4(+++)$ & - or 3,4 $(+)$ \\
& larvae & Amy3 & $3(+)$ & $3(++)$ \\
\hline
\end{tabular}

Levels of expression of amylase variants in the different parts of the midguts are indicated as $(-)$ for no expression, $(+)$ or $(++)$ for intermediate expression and $(+++)$ for strong expression.

In addition, in Taï 13-1610, there is a slight spatial shift in PMG expression between Amy1-2 and Amy3-4 (see arrow on Fig. 4). In adults, such a distribution was not found. The absence of Amy expression in the PMG (T404, some individuals from strain 371-1) should reflect variation in the map pattern. All of the observations are summarized in Table 4.

\section{Discussion and conclusion}

The data presented here clearly demonstrate the existence of a divergence in regulation of the Amy1-2 and Amy3-4 gene clusters which are located on different chromosomes in $D$. ananassae. Regulation occurs in two ways. First, a temporal differentiation, the Amy1-2 being mainly larval in contrast to the Amy3-4 expressed in adults. However, the differential expression is partial because some variants like Amy3 may be expressed in both stages, larval and adult. Secondly, there is a tissue-specific differentiation, the two groups of genes being differentially expressed in the midgut. In addition some sex- and age-related differentiation in Amy1-2 expression was observed in the adult midgut.

The experiments described above provide arguments supporting the existence of regulatory elements acting on temporal amylase expression in $D$. ananassae. These trans-acting factors are involved in Amy 1-2 repression in adult flies but the way they control amylase expression is still unknown. There is evidence for trans-acting regulators for temporal expression in various Drosophila genes (reviewed in Friedman et al., 1992). The urate oxidase (UO) genes of $D$. pseudoobscura, $D$. virilis and $D$. melanogaster have a temporal expression pattern different from one another. The genes of D. pseudoobscura and $D$. virilis were integrated in the $D$. melanogaster genome along with their own $5^{\prime}$ cis-regulatory elements. The transgenes were expressed in a similar temporal pattern as the acceptor species' UO gene (Wallrath \& Friedman, 1991). In this case, evolution of some trans-active factors was considered to be responsible for the species-specific temporal pattern, rather than cis-sequence modifications. Considering our data on $D$. ananassae, we may assume a similar evolution at the interpopulational level, not exclusive of cis-sequence evolution due to the high number of Amy gene copies in this species.

Although the regulatory phenomena of the amylases in $D$. ananassae are complex, it seems clear that these regulatory factors are partly responsible for the observed electrophoretic polymorphism. A geographical polymorphism for the active vs. inactive regulators (active regulators fixed in the Pacific region, polymorphism in Africa, and an increasing frequency of active repressors in Asia towards the Pacific) would partly explain the geographical pattern observed for adults (Da Lage et al., 1989). The high phenotypic diversity within African populations could be a consequence of the regulatory polymorphism.

In this study, we have provided evidence of repressive factors. However, additional regulatory mechanisms may exist and are perhaps antagonist: in the analysis of backcrosses between T404 (Amy 4) and the $F_{1}$ from $T 404 \times$ Tai 13-1610 (Amy 1,2,3,4) (Da Lage, 1990), some adult individuals with Amy1' protein were found, although this amylase is strictly larval in natural conditions. In this experiment, the Amy1' structural gene was brought by the T404 parent from the Pacific Ocean (active repressor for Amy1,2 in adults). It seems that the remaining African genetic background was able to activate this 
larval gene in adults through an unknown activator. Regulatory phenomena may also affect the Amy3-4 gene cluster (Fig. 1b), but at present we have no suitable strains to study this.

Tissue-specific expression in the midgut (AMG and PMG) appears to be in $D$. ananassae as in $D$. melanogaster and other species investigated (see Introduction). Some genes similar to the map system of $D$. melanogaster are likely to exist in $D$. ananassae. However, compared to the other species, there is a striking difference: the expression of amylase in the AMG or PMG in D. ananassae is clearly related to the differential regulation of the two clusters of genes, Amy1-2 and Amy3-4.

In $D$. melanogaster, in which the amylase gene is duplicated, the regulation has been extensively studied. However, compared to $D$. ananassae, the differences in relative activities of the two copies have not been found to be so demonstrative of a regulatory divergence. Doane (1969) found quantitative variation between the activities of the individual genes of the Amy duplication in developmental and tissue-specific expression. Klarenberg et al. (1986) have shown that tissue-specific expression in the midgut is influenced by food conditions. The two genes in the duplicated Amy locus had differential expression in larvae grown on a sugar-free medium, Amy3 being present in the AMG, in contrast to Amy6. On a food medium rich in sucrose, Amy3 and Amy6 were only expressed in a small region of the PMG. Matsuo and Yamazaki (1986) investigated the regulation of these duplicated genes, but their results show no clear differentiation of the genes. Thus, in any case described previously in Drosophila a differentiation as clear as in $D$. ananassae was found, which certainly results from the presence of two gene clusters of Amy genes located at different chromosomes. The results suggest that the Amy gene clusters underwent regulatory differentiation after the duplication occurred.

In some aspects the amylase system of $D$. ananassae actually resembles the duplicated Adh systems of species of the mulleri subgroup (Batterham et al., 1983a, 1983b, 1984; Mills et al., 1986) and the fourloci esterase system of D. montana (Roberts \& Baker, 1973; Baker, 1975, 1980) in which duplications were followed by tissue-specific and developmentally separate regulation.

Concerning other amylase systems, mammalian systems like those of mouse or man show some analogies with $D$. ananassae as they have a multigenic structure and variable copy number (Crerar \& Rooks, 1987; Meisler \& Ting, 1992; Da Lage et al., 1992 and in prep.). Adaptive interpretations of such a situation should be investigated in the light of these data, provided that knowledge of the natural resources used by $D$. ananassae can be improved. For example, tissue-specificity of some amylase genes could be linked to a substrate preference, as described by Zouros and van Delden (1982) for esterases of $D$. mojavensis. Preference in $\mathrm{pH}$ could also be involved, although our preliminary results (unpublished) were negative. A shift in metabolism related to the molecular organization of the two gene clusters could also explain why so many as four genes are functional in $D$. ananassae in contrast to a single active gene in $D$. pseudoobscura and $D$. miranda or two genes in $D$. melanogaster (Hawley et al., 1990). Further detailed step-by-step molecular analysis of the Amy gene clusters in D. ananassae has to be performed in order to understand the complexity of the phenotypic aspects of regulation described here.

\section{Acknowledgements}

We thank Rosette Goïame, Alice N'Guyen and Elisabeth Herniou for help in performing protein gels; Gilles Cariou, Brigitte Moreteau and Philippe Brabant for statistical advice.

\section{References}

ABRAHAM, 1. AND DOANE, w. w. 1978. Genetic regulation of tissue-specific expression of amylase structural genes in Drosophila melanogaster. Proc. Natl. Acad. Sci. U.S.A., 75, 4446-4450.

BAHN, E. 1967. Crossing over in the chromosomal region determining amylase isozymes in Drosophila melanogaster. Hereditas, 58, 1-12.

BAKER, w. K. 1975. Linkage desequilibrium over space and time in natural populations of Drosophila montana. Proc. Natl. Acad. Sci. U.S.A., 72, 4095-4099.

BAKER, w. K. 1980. Evolution of the alpha-esterase duplication within the montana subphylad of the virilis species group of Drosophila. Genetics, 94, 733-748.

BATTERHAM, P., LOVETT, J. A., STARMER, w. T. AND SUlliVAN, D. T. 1983a. Differential regulation of duplicated alcohol dehydrogenase genes in Drosophila mojavensis. Dev. Biol., 96, 346-354.

BATTERHAM, P., GRITZ, E., STARMER, W. T. AND SULliVAN, D. T. 1983b. Biochemical characterization of the products of the Adh loci of Drosophila mojavensis. Biochem. Genet., 21, 871-883.

BATTERHAM, P., CHAMBERS, G. K., STARMER, W. T. AND SUlLivan, D. T. 1984. Origin and expression of an alcohol dehydrogenase gene duplication in the genus Drosophila. Evolution, 38, 644-657.

BENKEL, B. F. AND HICKEY, D. A. 1986. Glucose repression of amylase gene expression in Drosophila melanogaster. 
Genetics, 114, 137-144.

BOROWSKY, R., BOROWSKY, B., MILANI, H. AND GREENBERG, P. 1985. Amylase variation in the salt marsh amphipod, Gammarus palustris. Genetics, 111, 311-323.

BROWN, C. J., AQUADRO, C. F. AND ANDERSON, w. W. 1990. DNA sequence evolution of the amylase multigene family in Drosophila pseudoobscura. Genetics, 126, $131-138$

CRERAR, M. M. AND ROOKS, N. E. 1987. The structure and expression of amylase genes in mammals: an overview. C.R.C. Crit. Rev. Biotech., 5, 217-227.

DA LAGE, J.-L. 1990. Polymorphisme, structure et régulation des gènes de l'amylase chez Drosophila ananassae et espèces affines. Ph.D. Thesis, University of Paris 7.

DA LAGE, J.-L., CARIOU, M.-L. AND DAVID, J. R. 1989. Geographical polymorphism of amylase in Drosophila ananassae and its relatives. Heredity, 63, 67-72.

DA LAGE, J.-L., LEMEUNIER, F., CARIOU, M.-L. AND DAVID, J. R. 1992. Multiple amylase genes in Drosophila ananassae and related species. Genet. Res., 59, 85-92.

DAIINOU, O., CARIOU, M.-L., DAVID, J. R. AND HICKEY, D. A. 1987. Amylase gene duplication, an ancestral trait in the Drosophila melanogaster species subgroup. Heredity, 59, 245-251.

DAVID, J. AND CLAVEL, M.-F. 1965. Interaction entre le génotype et le milieu d'élevage. Conséquences sur les caractéristiques du développement de la Drosophile. Bull. Biol. Fr. Belg., 99, 369-378.

DOANE, w. w. 1969. Drosophila amylases and problems in cellular differentiation. In: Hanly, E. W. (ed.) Problems in Biology: RNA in Development, pp. 73-109. University of Utah Press, Salt Lake City.

DOANE, W. W, TREAT-CLEMONS, L. G., GEMMiLl, R. M., MARTENSON, R. E., LEVY, J. N., HAWLEY, S. A., BUCHBERG, A. M. AND PAIGEN, K. 1983. Genetic mechanism for tissue-specific control of alpha-amylase expression in Drosophila melanogaster. In: Rattazzi, M. C., Scandalios, J. G. and Whitt, G. S. (eds) Isozymes: Current Topics in Biological and Medical Research, vol 9, pp. 63-90. Alan R. Liss, New York.

FRIEDMAN, T. B., BURNETT, J. B., LOOTENS, S., STEINMAN, R. AND WALlRATH, L. L. 1992. The urate oxidase gene of Drosophila pseudoobscura and Drosophila melanogaster: Evolutionary changes of sequence and regulation. $J$. Mol. Evol., 34, 62-77.

GUMUCIO, D. L., WIEBAUER, K., KALDWELl, R. M., SAMUelSON, L. C. AND MEISLER, M. H. 1988. Concerted evolution of human amylase genes. Mol. Cell. Biol., 8, 1197-1205.

HAWLEY, S. A., NORMAN, R. A, BROWN, C. J., DOANE, W. W., ANDERSON, W. W. AND HICKEY, D. A. 1990. Amylase gene expression in intraspecific and interspecific somatic transformants of Drosophila. Genome, 33, 501-508.

KiKKAWA, H. 1953. Biochemical genetics of Bombyx mori (silkworm). Adv. Genet., 5, 107-140.

KIKKAWA, H. 1964. An electrophoretic study on amylase in Drosophila melanogaster. Jap. J. Genet., 39, 401-411.

KLARENBERG, A. J. AND SCHARLOO, w. 1986. Nonrandom association between structural $A M Y$ and regulatory $M A P$ variants in Drosophila melanogaster. Genetics, 114
$875-884$.

KLARENBERG, A. J., VISSER, A. J. S., WILLEMSE, M. F. M. AND SCHARLOO, w. 1986. Genetic localization and action of regulatory genes and elements for tissue-specific expression of $\alpha$-amylase in Drosophila melanogaster. Genetics, 114, 1131-1145.

KLARENBERG, A. J., JACOBS, P. J. M., VERMEULEN, C. AND SCHARLOO, w. 1988. Genetic and dietary regulation of tissue-specific expression patterns of alpha amylase in larvae of Drosophila melanogaster. Comp. Biochem. Physiol., 89B, 143-146.

LAULIER, M. 1988. Génétique et systématique évolutives du complexe d'espèces Sphaeroma hookeri Leach, Sphaeroma levii Argano et Sphaeroma rugicauda Leach (Crustacés, Isopodes Flabellifères). 1. Génétique formelle de onze locus enzymatiques. Génét. Sél. Évol, 20, 63-74.

MATSUO, Y. AND YAMAZAKı, T. 1986. Genetic analysis of natural populations of Drosophila melanogaster in Japan. VI. Differential regulation of duplicated amylase loci and degree of dominance of amylase activity in different environments. Jap. J. Genet., 61, 543-558.

MiLls, L. E., BATTERHAM, P., ALEGRE, J., STARMER, w. T. AND SUlLIVAN, D. T. 1986. Molecular genetic characterization of a locus that contains duplicate $A D H$ genes in Drosophila mojavensis and related species. Genetics, 112, 295-310

OXFORD, G. s. 1986. Multiple amylase loci in Asellus (Crustacea: Isopoda): Genetics and linkage. Heredity, 56, $105-110$.

PAyant, V., ABUKashawa, S., Sasseville, M., BenKel, B. HICKEY, D. AND DAVID, J. 1988. Evolutionary conservation of the chromosomal configuration and conservation of amylase genes among eight species of the Drosophila melanogaster species subgroup. Mol. Biol. Evol., 5, 560-567.

POPE, G. J., ANDERSON, M.D. AND BREMNER, T. A. 1986. Constancy and divergence of amylase loci in four species of Tribolium (Coleoptera, Tenebrionidae). Comp. Biochem. Physiol., 83B, 331-333.

PoWell, J. R. AND LICHTEnfels, J. M. 1979. Population genetics of Drosophila amylase. I. Genetic control of tissue-specific expression in D. pseudoobscura. Genetics, 92, 603-612.

ROBERTS, R. M. AND BAKER, W. K. 1973. Frequency distribution and linkage desequilibrium of active and null esterase isozymes in natural populations of Drosophila montana. Am. Nat., 107, 709-726.

SOKAL, R. R. AND ROHLF, F. J. 1995. Biometry, 3rd edn. Freeman and Co., New York.

WALlRATH, L. R. AND FRIEDMAN, T. B. 1991. Species differences in the temporal pattern of Drosophila urate oxidase gene expression are attributed to trans-acting regulatory changes. Proc. Natl. Acad. Sci. U.S.A., 88, 5489-5493.

ZOUROS, E. AND VAN DELDEN, w. 1982. Substrate-preference polymorphism at an esterase locus of Drosophila mojavensis. Genetics, 100, 307-314. 